\title{
Implications of the COVID-19 Pandemic on the Mental Health and Professional Psychomotor Skills of Dental Students
}

\author{
Fahad Abdulaziz Alrashed (D) \\ Kamran Sattar (iD ${ }^{2}$ \\ Syed Rashid Habib (D) ${ }^{3}$ \\ Tauseef Ahmad (iD ${ }^{2}$ \\ Abdulaziz Saud Al Rashoud ${ }^{3}$ \\ Turki ali Y SAFHI ${ }^{3}$ \\ Abdulrhman Hamad M Almajed ${ }^{3}$ \\ Hamad Ali H Alnafisah ${ }^{3}$ \\ Norah Hamad Alharbi ${ }^{3}$ \\ Abdulrahman Alsubiheen ${ }^{4}$ \\ 'Department of Cardiac Sciences, \\ College of Medicine, King Saud \\ University, Riyadh, Saudi Arabia; \\ ${ }^{2}$ Department of Medical Education, \\ College of Medicine, King Saud \\ University, Riyadh, Saudi Arabia; \\ ${ }^{3}$ Department of Prosthetic Dental \\ Sciences, College of Dentistry, King Saud \\ University, Riyadh, Saudi Arabia; \\ ${ }^{4}$ Department of Rehabilitation Sciences, \\ College of Applied Medical Sciences, King \\ Saud University, Riyadh, Saudi Arabia
}

Purpose: To estimate dental students' self-perception of mental well-being (MWB) and its effects on their clinical psychomotor skills (CPS) once they (or their family members) get infected with COVID-19.

Materials and Methods: This is a cross-sectional $(n=268)$ study from a public dental college in Riyadh. We collected data on MWB and CPS. An 18-item online survey was used to collect the responses from the participants. The inter-rater reliability for the finalised survey came out to be 0.86 .

Results: The participants (54.3\%) who were infected with COVID-19 recorded that their CPS were significantly affected (almost 4 times higher) as compared to others $(O R=4.02$; $P=0.0004)$. However, $42.2 \%$ reported infection control measures at clinics resulted in bringing significant $(O R=2.22, P=0.04)$ psychological upsets, for those who were infected with COVID-19. Participants (45.1\%) also reported that they have difficulty in recalling old memories or information due to the COVID-19 pandemic; among them, $46.7 \%$ were the ones who (and/or any family member) were exposed to COVID-19.

Conclusion: The study spotlighted the extent of dental students' MWB and its significant effect on their CPS once (themselves or a family member) infected with COVID-19. Moreover, levels of infection control measures at clinics resulted in psychological upsets for dental students.

Clinical Significance: The issue is fundamental as participants enter the clinical workforce and face the ever-increasing demands of dental practice.

Keywords: dental students, clinical psychomotor skills, mental well-being, pandemic, COVID-19

\section{Background}

In the midst of confining due to the COVID-19 pandemic, regular educational activities for students of undergraduate and postgraduate dentistry were significantly disrupted around the world. ${ }^{1}$ Currently, healthcare in general, and oral healthcare in particular, is being profoundly reshaped by a convergence of economic, demographic, and technological trends. ${ }^{2}$ In such demanding and challenging times, E-learning, and in particular, the use of internet sources, boost learning and comprehension for students. ${ }^{3}$ This transformation was a rapid response, so was not devoid of limitations and drawbacks, specialy for academic fields requiring face-toface sessions. Acquiring authentic dental education ${ }^{4}$ requires realistic, practical participation. Students' understanding of the topic of dental education tends to be
Correspondence: Fahad Abdulaziz Alrashed

Department of Cardiac Sciences, College of Medicine, King Saud University, Riyadh, Saudi Arabia

Email faaalrashed@ksu.edu.sa 
improved by pragmatic involvement. ${ }^{5}$ Hence, this recent transition from face-to-face classes on campus to online distance learning sessions not only brought facilitation in the demanding times as well as generated challenges for dental students to cope with their clinical psychomotor skills (CPS). ${ }^{6}$ The intern doctor and the patient, as well as the teacher, will have frequent interaction. In a pandemic situation, this is also the most daunting aspect of dental education to contend with. ${ }^{7}$

Dental environments have particular features that necessitate extra attention to infection control. Although dentists are knowledgeable, they are yet prone to various infectious diseases, as hepatitis B and C. Many other occupations do not have to worry about infection to the same extent. ${ }^{7-9}$ Dental practitioners and dental students face an elevated risk from dental patients for viral infections because their practice and everyday training require face-to-face contact with patients involving contact with saliva and blood. SARS-CoV-2 transmission can thus occur during dental procedures through inhalation of infected individuals' aerosol/droplets or direct interaction with mucous membranes, oral fluids, and contaminated instruments and surfaces. ${ }^{9,10}$ The WHO was urged by the unique and uncertain existence of this pandemic to warn about the potential outbreak of workplace stress and psychiatric disorders. ${ }^{11}$ The New York Times prompted that dentists are the most vulnerable individuals when it comes to COVID-19 risk. $^{12}$

Human beings are mostly living in close association with other family members, depending on various cultures. Hence, there are always chances of any viral disease to affect mentally and physically from one person to another in a family or group of people. When it comes to COVID19 , the transmission rate or attack gets higher, with worse clinical outcomes in the family cluster. ${ }^{13}$ Individuals with COVID-19 infection (at risk) family members were threefold more likely to have mental health-related symptoms. $^{14}$

Dental education is progressing at a rapid rate. ${ }^{15}$ Dental students and teachers are also using these available digital resources for communication on an everyday basis. Despite these new developments focused on educationrelated issues, no information remains vivid about the actual effect of these resources on the learning development of students. Research in the domains of dentistry not only allows for reliable monitoring of the prevalence and spread of oral disease, but it also permits stakeholders for the preparation and evaluation of various educational challenges. ${ }^{16}$ Moreover, the negative impacts of the COVID-19 pandemic on dental students' performance in clinical settings are not much explored. Studies have shown good experiences but in with grave limitations. ${ }^{17}$

At College of Dentistry, we have a five-year program. Students are required to attend clinical training in different courses, with real and simulated patients and mannequins, which starts from 2nd year onwards. According to our best knowledge, this is the first study in Saudi Arabia, and we explored dental students' self-perception of MWB and its effects on their CPS once they (or their family members) get infected with COVID-19. This is significant, as there is currently very little published work available, and the findings from this investigation can improve current and post-pandemic learning and teaching, especially in programs that rely heavily on clinical training. This is especially significant in undergraduate dental education.

\section{Methods}

\section{Study Design and Settings}

This was a cross-sectional type observational study conducted from September to December 2020.

\section{Study Participants}

A total of 309 participants agreed for this study. We employed a convenience sampling. Inclusion criteria consisted of; undergraduated dental students, from year 2 to 5 . Dental interns were also included in this study Dental students who were in year 1 were not requested as they are not getting trained in the dental clinics for clinical psychomotor skills. All the agreed participants were informed about the objectives of the study. Later on, we included completed responses from 268 participants for this study. All the participants were informed about the study and an ethical approval was also received from the institutional review board (IRB \# E-20-5321). Verbal, as well as written consents were obtained from all participants before data collection. This study was conducted in accordance with the Declaration of Helsinki.

\section{Instrument}

A panel of 3 experts working as medical educationists held a 4 hour meeting to form survey items. Initially, 30 item survey (1st version) was prepared in the light of available literature. In 2 subsequent meetings (week apart), this panel discussed and agreed upon deleting 3 items and keep 27 items for the 2 nd version. To achieve reliability 
and validity of the survey items, the 2 nd version was pilot tested with 17 students from year 2 nd and $3 \mathrm{rd}$, and 4 interns of College of Dentistry. After standardising all items, reasonably a good inter-rater reliability score was achieved (Cronbach's $\alpha=0.71$ ). Face validation of the questionnaire was performed by two independent experts among the team of experts. After carefully evaluating the results from the pilot study, face validation of the instrument was carried out and 5 items were removed, as they were found to be duplicating or ambiguous. Thus, a 22 item survey was used to collect the data from the agreeing participants. The inter-rater reliability for the finalised survey came out to be 0.86 .

We used Google forms for collecting the data. The finalised questionnaire sought responses using a FivePoint Likert Scale. ${ }^{18}$ The demographic details (using 4 items) were collected for gender, age, study level, and a question asking the participants, "Have you and or your family member were infected with COVID-19". Here family member depicts blood relatives living in the close vicinity of the participants (Table 1). The following 11 items were designed to explore participants' personal feelings amid the COVID-19 pandemic outbreak (Table 2). Whereas the last part ( 7 items) addressed the items related to the participants' interaction with patients at the dental clinic and their knowledge/skills during the COVID-19 pandemic outbreak (Table 3).

Table I Demographic Information of Participants

\begin{tabular}{|l|l|l|}
\hline Variable & Description & $\begin{array}{l}\text { Number } \\
\text { (\%) }\end{array}$ \\
\hline Gender & $\begin{array}{l}\text { Male } \\
\text { Female }\end{array}$ & $\begin{array}{l}\text { III(4I.4) } \\
157(58.6)\end{array}$ \\
\hline Age & $\leq 20$ & $7(2.6)$ \\
& 21 to 25 & $259(96.6)$ \\
26 to 30 & $2(0.7)$ \\
\hline Level of Study & 2nd Year & $6(2.23)$ \\
& 3rd Year & $49(18.3)$ \\
& 4 th Year & $68(25.4)$ \\
& 5th Year & $78(29.1)$ \\
Intern & $67(25.0)$ \\
\hline Have you and/or your *family member & Yes & $92(34.3)$ \\
were infected with COVID-19 & No & $176(65.7)$ \\
\hline
\end{tabular}

Notes: *Blood relative, living in close vicinity.

\section{Data Collection}

Participant's responses were collected using online distribution of the questionnaire. This online survey consisted of informed consent stating that the participation was on a volunteer basis. There was no incentive for the participants. The collected information was kept secure and confidential.

\section{Statistical Analysis}

Once the data were collected, we entered and analysed it using SPSS version 22.0 (IBM. Armonk, NY, USA). The prevalence of a result variable was estimated along with confidence intervals of 95\%. Pearson's chi-square test and odds ratios (ORs) were used to determine and quantify the associations between a definite outcome and the variables being considered. During the entire study, the statistical significance level has been established as $\mathrm{P}<0.05$.

\section{Results}

A total of 268 (out of 309 initially agreed participants) completed surveys were included with a response rate of 86.73\%. Among 268 participants, 111 (41.4\%) were male, and 157 (58.6\%) female. The most (96.6\%) contributing age group was 21 to 25 . Out of the total participants, 92 (34.3\%) reported a direct or indirect association of infection (Table 1). It was recorded that male participants have a higher $(52.2 \%)$ rate of exposure as were themselves and/ or their family members infected with COVID-19, as compared to female participants who were themselves (and/or any of their family members) were infected $(47.8 \%)$. This shows a significantly higher rate in male participants $(\mathrm{OR}=1.95 ; \mathrm{P}=0.01)$ (Table 1$)$

It was also found that the age group (21-25 years) had more chances for infection $(\mathrm{OR}=3.25 ; \mathrm{P}=0.27)$.

Utilization of the online resources (to get information about coronavirus) was 2.6 times significantly higher $(\mathrm{OR}=2.61 ; P=0.006)$ by the infected participants, as compared to those who remained uninfected (Table 4).

Experience of insomnia was found to be 3.53 times more among those who themselves (or a family member) were infected. Concerning the self-reported depression during the current pandemic, $23.1 \%$ of the participants stated positive affirmation, and among them, the ones who were directly exposed have stated prevalence of depression $(O R=1.78 ; P=0.06)$. Moreover, $37.2 \%$ of students have perceived feeling of hopelessness, and among 


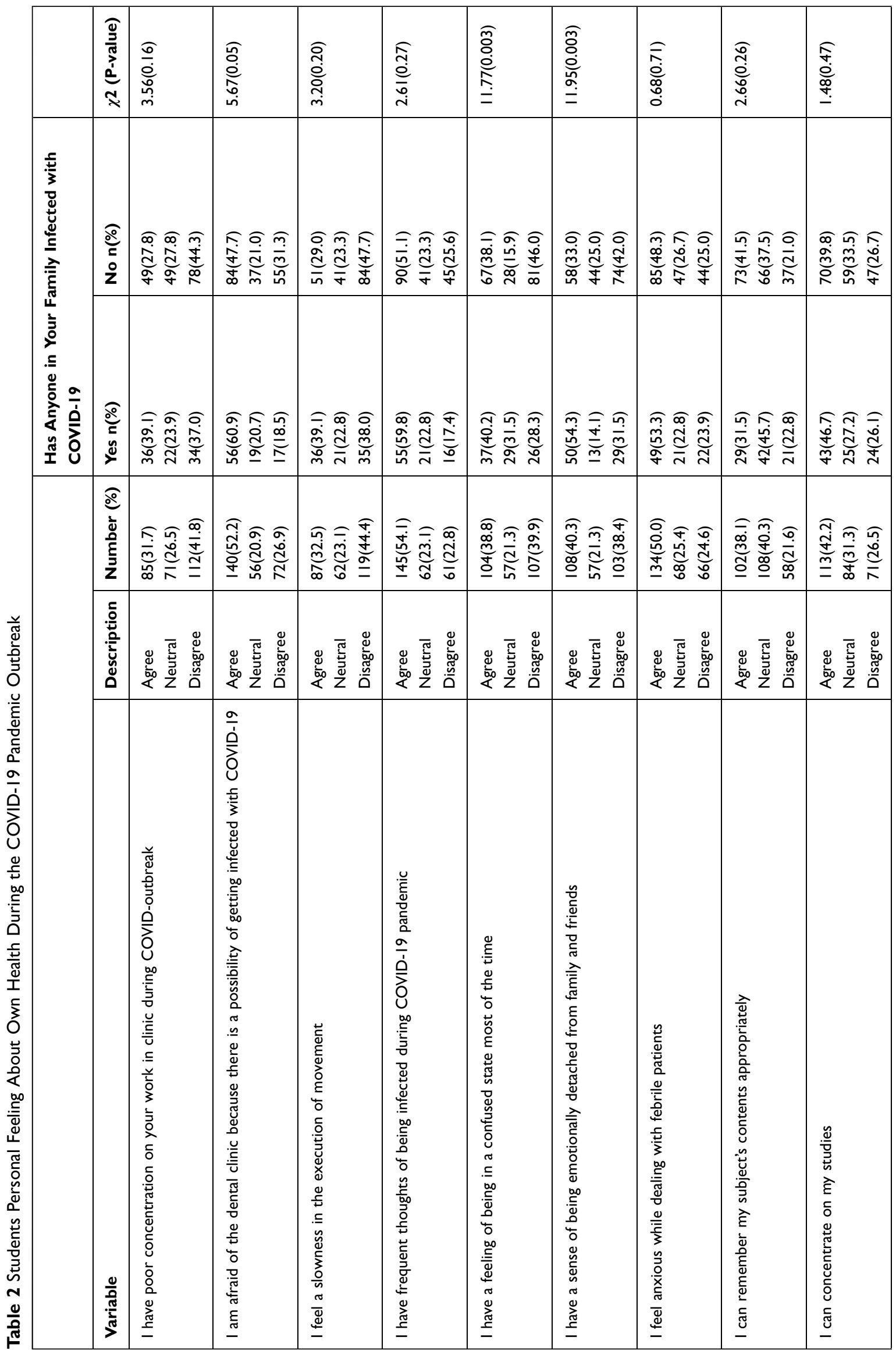




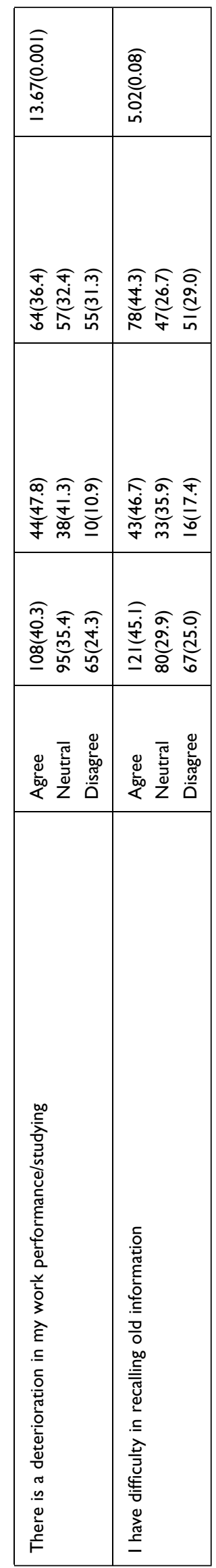

them a higher prevalence rate was found among those who were infected with COVID-19 (OR=2.43; $P=0.002$ ).

The participants $(54.3 \%)$ who were infected with COVID-19 recorded that their CPS were significantly affected (almost 4 times higher) during the pandemic as compared to others $(O R=4.02 ; P=0.0004)$ (Table 4). Furthermore, $42.2 \%$ reported infection control measures required to practice at clinics affecting psychologically, which is significantly high $(O R=2.22, P=0.04)$ for those who were infected with COVID-19. However, $50.4 \%$ of participants were reported as ready to treat patients during the current pandemic situation; among them was not significant of those who themselves (and/or any family member) were exposed to coronavirus $(O R=1.97 ; P=0.06)$ (Table 4).

Table 2 summarises the personal feeling about own health during the COVID-19 pandemic outback. This study found that most $(52.2 \%)$ of the participants were found to be afraid of their training and practice at dental clinics because there was a possibility of coronavirus infection, among these a significantly high $(\mathrm{P}=0.05)$ number was of those students $(60.9 \%)$ who themselves (or any family member) were exposed to COVID-19. In the current study, $54.1 \%$ of students reported that they have frequent thoughts of being infected during the COVID19 pandemic. $38.8 \%$ of students agreed that they have the feeling of being in a confused state most of the time, and among them, $40.2 \%$ were those students who themselves (or any family member) were infected with COVID- 19. This was statistically significant $(\chi 2=11.7 ; \quad \mathrm{P}=0.003)$. Similarly, $40.3 \%$ of students reported that they have a sense of being emotionally detached from family and friends due to coronavirus, this type of feeling was reported mostly (54.3\%) by those who themselves (or any family member) were infected with COVID-19 $(\chi 2=11.95 ; \mathrm{P}=0.003)$. Furthermore, $45.1 \%$ of participants reported that they have difficulty in recalling old memories or information due to the COVID-19 pandemic; among them $46.7 \%$ were the ones who (or any family member) were infected with COVID-19.

Table 3 summaries the participants' knowledge and skills and the way of interaction with patient at the dental clinical during the COVID-19 pandemic. Majority of the participants (91.8\%) inquired the visiting patients about fever, cough, or recent travel history during regular checkups. Similarly, $82.8 \%$ of the participants agreed about using hand sanitisation more frequently while at the dental clinic. Furthermore, $60.8 \%$ of students with no history of 


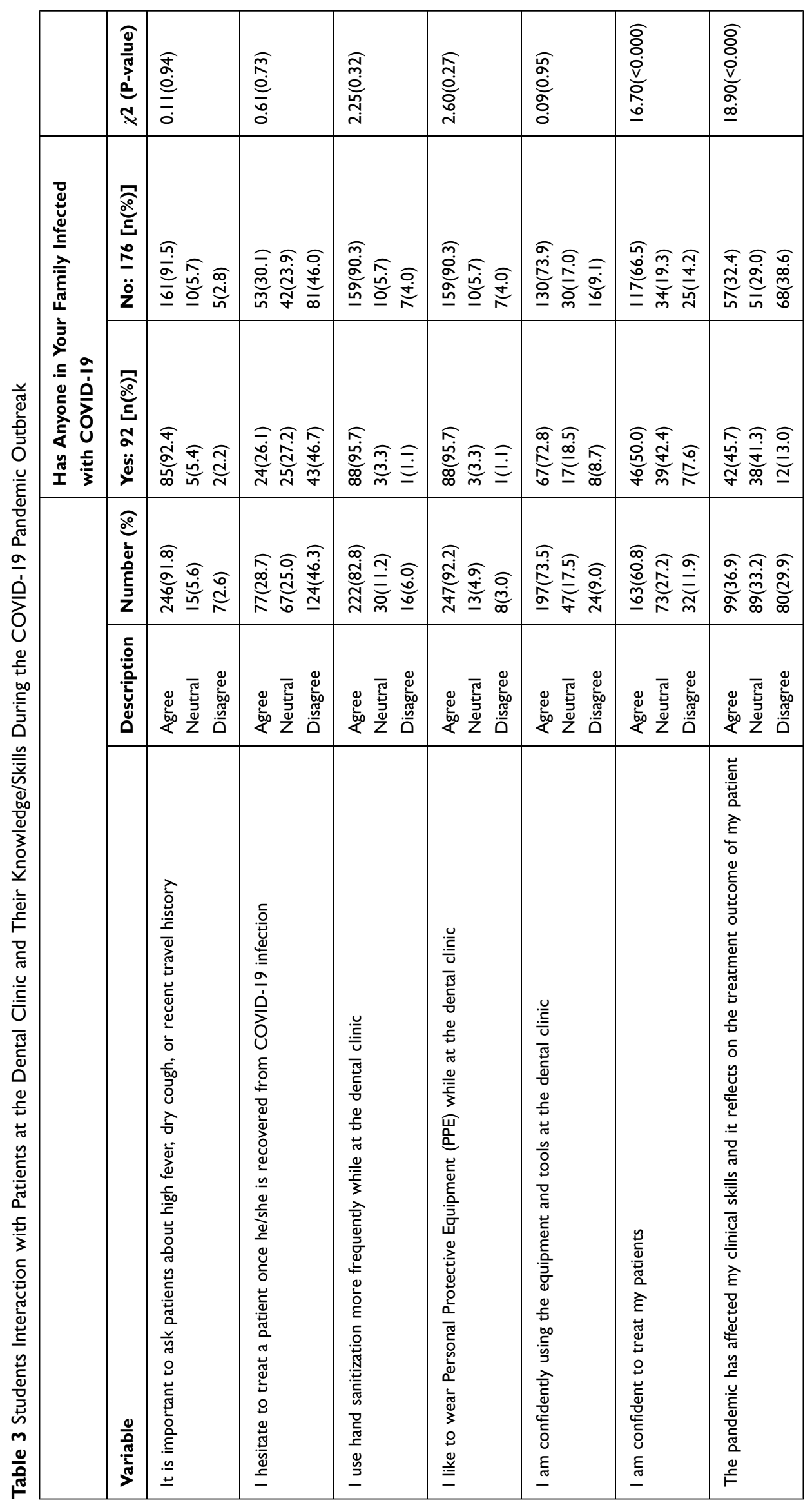




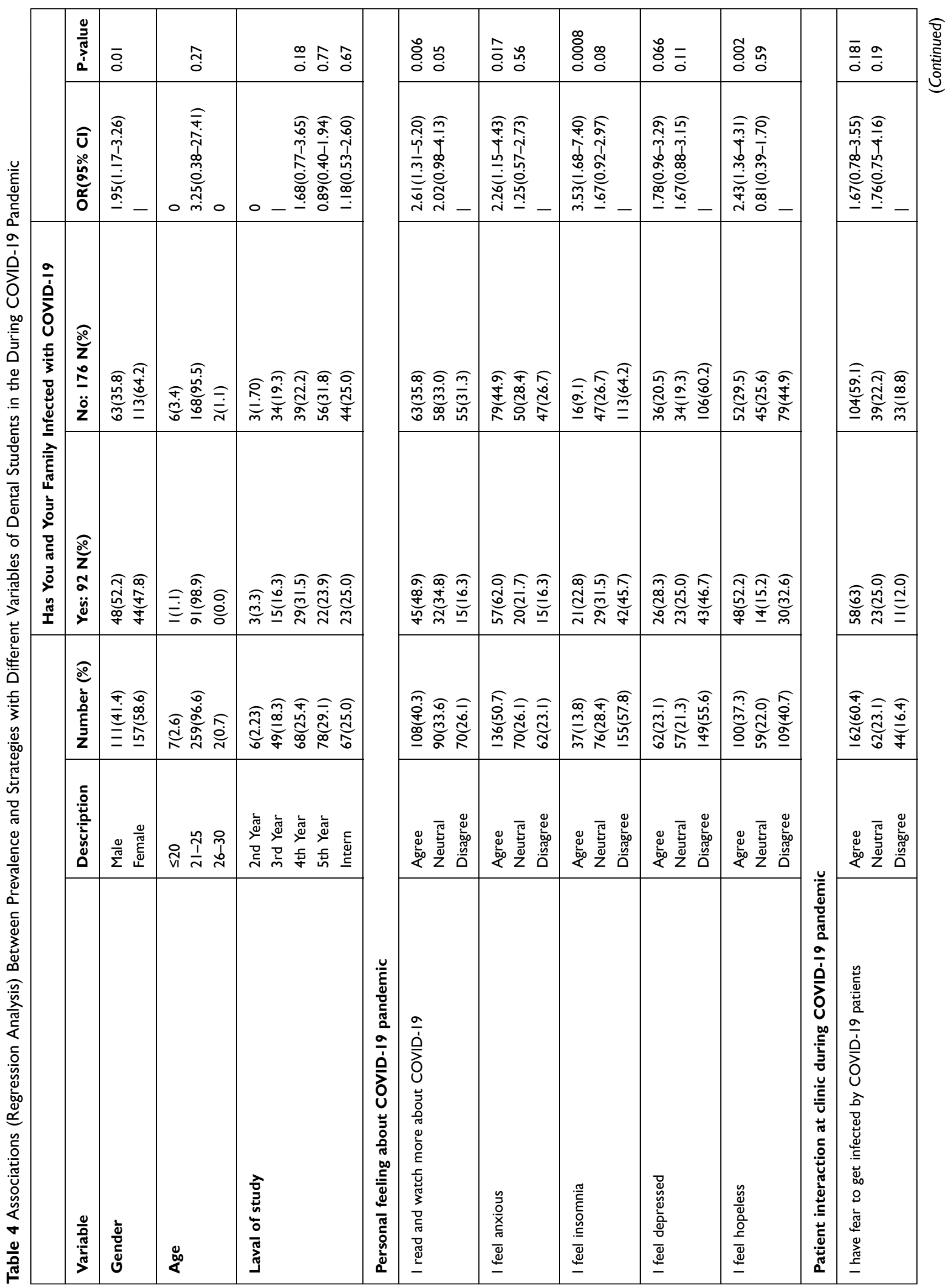




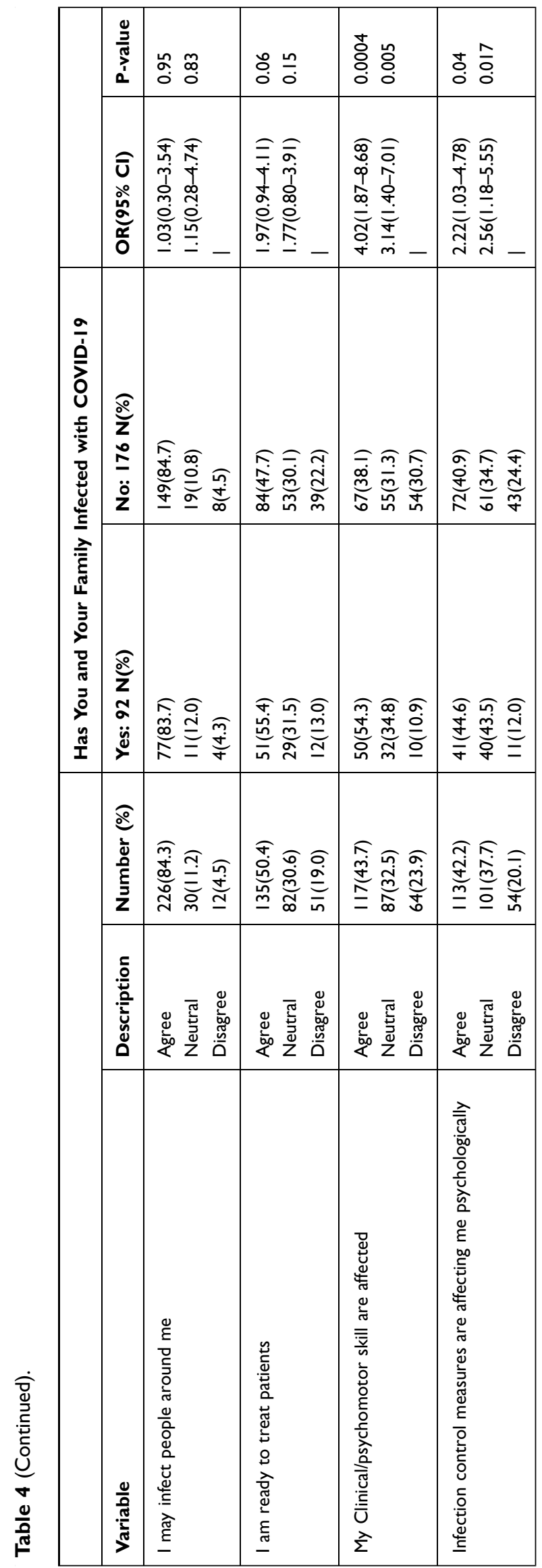

COVID-19 had much more confidence to treat patients than those who had a history of infection of COVID-19 $(\chi 2=16.70 ; P=<0.000)$. Only $36.9 \%$ reported that the COVID-19 pandemic had affected their CPS, and among them, a significantly high percentage was for those who themselves (or any family member) were exposed $(\chi 2=18.90 ; P=<0.000)$ with COVID-19.

\section{Discussion}

Behavioral and social methods are being used in many countries to monitor and control the transmission of coronavirus disease. In health-care facilities, both infected and non-infected patients are isolated. If they are capable, patients can only interact with their family members through mobile phones or electronic tablets.

Supporting patients allow physicians, students (medical and dental), and nurses who are already stressed by the emergency load to serve humanity by treating the ailing community, ${ }^{19}$ but it can also be emotionally draining. During the current pandemic, doctors are also cared for at home, mainly by their close family and relatives.

In this study, the participants who themselves (or any family member) were infected had a higher inclination towards gathering information through videos ${ }^{20}$ and other online resources ${ }^{21}$ to get coronavirus information. Similarly, another study from Pakistan stated that due to the limited data available as COVID-19 preventive guidance for dental practitioners, dental students often turn to the internet for details. ${ }^{22}$ It is noteworthy that similar findings were reported in a study from China, stating, social media and TV were also among the preferred ways to gather information regarding pandemic, ${ }^{23}$ and also in Saudi Arabia. ${ }^{24}$ In the current study, we found that most dental students (if any of their family member has infected with coronavirus) were anxious and recorded for having more than 2 times high anxiety levels as compared to other respondents (whose family members were not infected). Two other published studies from China and Albania reported a similar finding. ${ }^{25,26}$ The dental clinical students were worried about their family members and friends to get infected hence, experienced anxiety and insomnia. $^{27}$

The current study reported that dental clinical students were affected by fear of contagion and of infecting family members and friends and this resulted in a high level of insomnia problem (3.53 times higher). Similarly, the findings are in conjunction with results from another study. ${ }^{27}$ In addition, the effect of insomnia has been linked to 
negative aspects of the doctor-patient relationship. ${ }^{28}$ The prevalence of depression in the dental students was recorded to be 1.78 times high if any family member had been infected with the virus, which showed the similar significant effect in another study. ${ }^{29}$ Individuals may become hopeless as a result of stressful life events, traumas, depressive symptoms, and anxiety. ${ }^{30}$ Anxiety levels in the state are closely linked to traumatic incidents, events that last a long time and are unpredictable, such as a pandemic, can exacerbate anxiety and hopelessness. In this study, there is a significant correlation, as the dental students (and any of their family members), was infected with the coronavirus, they were more hopeless ( 2.43 times higher). A similar finding reported in a previously published study. ${ }^{31}$ On March 11, 2020, the coronavirus disease 2019 (COVID-19) epidemic was declared a pandemic. Several dental clinics in the affected countries have closed or are only offering emergency services. ${ }^{32}$ Several facilities in some of the affected nations, however, continue to provide routine dental care. ${ }^{32}$ In the current study, most of the dental clinical students reported that their clinical and psychomotor skills were affected badly due to coronavirus, among them more affected were those students who themselves or any family members were infected with COVID19. These results were consistent with previous international findings. ${ }^{33,34}$

This study shows most participants agreed about using hand sanitisation more frequently while at the dental clinic. Findings from another study ${ }^{35}$ stated that the majority of participants recommended using disinfectants regularly between dental visits. The majority of our study participants also asked patients about fever, cough, or recent travel history during regular checkups at dental clinics. Similar reports were found, emphasising dental staff to inquire about their current health condition before their scheduled appointment. ${ }^{36}$

Dentistry is an example of such vocations where person-to-person interaction is inevitable. The discipline of dentistry uses CPS teaching models. ${ }^{37}$ Despite the fact that in current times various modern training resources like mannequins and models are available still, we do require doctor-patient interaction for the learners' excellence. The majority of students viewed clinical training practices as exposing them to the possibility of contracting COVID-19 infection. ${ }^{38}$ Based on our results, the CPS acquisition was affected, as reported by $36.9 \%$ of participants. Moreover, this was predominantly higher (almost 4 times higher) as the majority of the participants who were infected with
COVID-19 recorded that their CPS were significantly affected during the pandemic as compared to others. Such findings are in conjunction with results from another study. ${ }^{39}$

Cognitive function impairment is also a consequence of the COVID-19 pandemic. Our participants reported that they have difficulty recalling old memories or information due to the COVID-19. These results were consistent with previous international findings. ${ }^{40}$ COVID-19-affected patients have been related to a higher risk of cognitive impairment after resolving the primary infection, according to previous studies. ${ }^{41}$ The cognitive impairment reported in the earlier studies suggests the need for longterm follow up of the COVID-affected subjects. ${ }^{42,43}$

Widespread reports from the published work concluded that depression affects people of all ages and is one of the leading causes of sickness and disability. It is also to blame for serious life issues, and both attempted and completed suicides. ${ }^{44,45}$ Participants in our study reported being depressed. This was consistent with various published works in the recent past where dental students were reported to be depressed. ${ }^{46,47}$ Hakami et al ${ }^{48}$ identified that the prevalence of high levels of depression among dental students illustrates the need for psychological empowerment measures that involve institutional therapy services. $^{48}$

\section{Limitations and Implications}

Findings from one healthcare institute limit the generalizability of important outcomes. Nevertheless, offering safe dental services to patients while also protecting dentists and healthcare staff, is crucial. This all can be highlighted, stressed with practical measures targeting mental wellbeing resulting in improved clinical psychomotor skills of learners.

\section{Conclusion}

The risk of cross-infection between dental practitioners and patients is high due to the characteristics of dental settings. This risk is amplified as the current pandemic poses risk of COVID-19 infection within healthcare community. Strict and reliable guidelines on the prevention of infections are urgently required for dental practices and hospitals in countries/regions (potentially) affected by COVID-19. We conclude that the potential risk arising from COVID-19 to the dental students' MWB (affecting their CPS) is higher, especially during clinical performance. 
This study highlighted the magnitude of dental students' MWB and its substantial influence on their CPS once (themselves or a family member) infected with COVID-19. Additionally, levels of infection control measures at clinics resulted in psychological upsets for dental students, who find it difficult to recall old memories or information.

\section{Ethics Approval and Consent to Participate}

The study was approved by the institutional review board college of medicine, KSU. Before completing their responses on the questionnaire, all participants were provided with a written consent to participate in the study.

\section{Acknowledgment}

The authors extend their appreciation to the Deputyship for Research and Innovation, "Ministry of Education in Saudi Arabia for funding this research work through the project number IFKSURG-2020-145.

\section{Disclosure}

The authors report no conflicts of interest in this work.

\section{References}

1. Machado RA, Bonan PRF, Perez D, et al. COVID-19 pandemic and the impact on dental education: discussing current and future perspectives. Braz Oral Res. 2020;34:e083. doi:10.1590/1807-3107bor2020.vol34.0083

2. Shetty V, Yamamoto J, Yale K. Re-architecting oral healthcare for the 21st century. $J$ Dent. 2018;74:S10-S14. doi:10.1016/j. jdent.2018.04.017

3. Cardall S, Krupat E, Ulrich M. Live lecture versus video-recorded lecture: are students voting with their feet? Acad Med. 2008;83 (12):1174-1178. doi:10.1097/ACM.0b013e31818c6902

4. Hanks S, Cotton D, Spowart L. Leadership in dental practice: a three stage systematic review and narrative synthesis. $J$ Dent. 2020;102:103480. doi:10.1016/j.jdent.2020.103480

5. Russell MD, Bill JM, Orr MTS. The efficacy of practical participation in undergraduate dental education. J Dent. 1996;24(1):137-139. doi:10.1016/0300-5712(95)00064-X

6. Marshall AL, Wolanskyj-Spinner A. COVID-19: challenges and opportunities for educators and generation Z learners. Mayo Clin Proc. 2020;95(6):1135-1137. doi:10.1016/j.mayocp.2020.04.015

7. Chang T-Y, Hong G, Paganelli C, et al. Innovation of dental education during COVID-19 pandemic. J Dent Sci. 2021;16(1):15-20. doi:10.1016/j.jds.2020.07.011

8. Tay JRH, Ng E, Ong MMA, et al. A risk-based approach to the COVID-19 pandemic: the experience in National Dental Centre Singapore. Front Med. 2020;7:562728. doi:10.3389/fmed.2020.562728

9. Izzetti R, Nisi M, Gabriele M, et al. COVID-19 transmission in dental practice: brief review of preventive measures in Italy. $J$ Dent Res. 2020;99(9):1030-1038. doi:10.1177/0022034520920580

10. Consolo U, Bellini P, Bencivenni D, et al. Epidemiological aspects and psychological reactions to COVID-19 of dental practitioners in the Northern Italy Districts of Modena and Reggio Emilia. Int J Env Res Public Health. 2020;17(10):3459.
11. WHO. WHO Director-General's opening remarks at the media briefing on COVID-19; 2020. Available from: https://www.who.int/dg/ speeches/detail/who-director-general-sopening-remarks-at-the-mediabriefing-on-covid-19-11-march2020. Accessed May 28, 2021.

12. Gamio L. The workers who face the greatest coronavirus risk. The New York Times. New York: New York Times 2020.

13. Yi B, Fen G, Cao D, et al. Epidemiological and clinical characteristics of 214 families with COVID-19 in Wuhan, China. Int J Infect Dis. 2021;105:113-119. doi:10.1016/j.ijid.2021.02.021

14. Gill PK, Du C, Khan F, et al. The psychological effects of COVID-19 spread in young Canadian adults. Int $J$ Soc Psychiatry. 2021;20764020988878. doi:10.1177/0020764020988878

15. Lynch CD, Blum IR, Wilson NHF. Leadership in dental education. $J$ Dent. 2019;87:7-9. doi:10.1016/j.jdent.2019.07.011

16. Hogan R, Goodwin M, Boothman N, et al. Further opportunities for digital imaging in dental epidemiology. J Dent. 2018;74:S2-S9. doi:10.1016/j.jdent.2018.04.018

17. Santos GN, Leite AF, Figueiredo PT, et al. Effectiveness of E-learning in oral radiology education: a systematic review. $J$ Dent Educ. 2016;80(9):1126-1139. doi:10.1002/j.0022-0337.2016.80.9. tb06195.x

18. Zante B, Hautz WE, Schefold JC, Bilotta F. Physiology education for intensive care medicine residents: a 15-minute interactive peer-led flipped classroom session. PLoS One. 2020;15(1):e0228257. doi:10.1371/journal.pone.0228257

19. Khanagar SB, Alfadley A. Psychological impact of the COVID-19 pandemic on dental interns in Riyadh, Saudi Arabia: a cross-sectional survey. Int J Clin Pediatr Dent. 2020;13(5):508-512. doi:10.5005/jpjournals-10005-1773

20. Abdulghani HM, Haque S, Ahmad T, et al. A critical review of obstetric and gynecological physical examination videos available on YouTube: content analysis and user engagement evaluation. Medicine. 2019;98(30):e16459. doi:10.1097/MD.0000000000016459

21. Alsenaidy A, Tauseef A. A review of current state M Government in Saudi Arabia. Glob Eng Technol Rev. 2012;2(2):5-8.

22. Ghai S. Are dental schools adequately preparing dental students to face outbreaks of infectious diseases such as COVID-19? J Dent Educ. 2020;84(6):631-633. doi:10.1002/jdd.12174

23. Huynh G, Nguyen T, Tran V, et al. Knowledge and attitude toward COVID-19 among healthcare workers at District 2 Hospital, Ho Chi Minh City. Asian Pac J Trop Med. 2020;13(6):260-265. doi:10.4103/ 1995-7645.280396

24. Ahmad T, Sattar K, Akram A. Medical professionalism videos on YouTube: content exploration and appraisal of user engagement. Saudi J Biol Sci. 2020;27(9):2287-2292. doi:10.1016/j.sjbs.2020.06.007

25. Mechili EA, Saliaj A, Kamberi F, et al. Is the mental health of young students and their family members affected during the quarantine period? Evidence from the COVID-19 pandemic in Albania. J Psychiatr Ment Health Nurs. 2020;28:317-325. doi:10.1111/jpm. 12672

26. Özdin S, Bayrak özdin Ş. Levels and predictors of anxiety, depression and health anxiety during COVID-19 pandemic in Turkish society: the importance of gender. Int J Soc Psychiatry. 2020;66 (5):504-511. doi:10.1177/0020764020927051

27. Abdulah DM, Musa DH. Insomnia and stress of physicians during COVID-19 outbreak. Sleep Med. 2020;2:100017. doi:10.1016/j. sleepx.2020.100017

28. Azzez SS, Abdulah DM, Piro RS, et al. Sleep severity and fatigue manifestations in relation to the doctor-patient relationship. Sleep Med. 2019;58:13-17. doi:10.1016/j.sleep.2019.02.015

29. Hossain MM, Tasnim S, Sultana A, et al. Epidemiology of mental health problems in COVID-19: a review. F1000Research. 2020;9:636. doi:10.12688/f1000research.24457.1

30. Mathew AR, Pettit JW, Lewinsohn PM, et al. Co-morbidity between major depressive disorder and anxiety disorders: shared etiology or direct causation? Psychol Med. 2011;41(10):2023-2034. doi:10.1017/ S0033291711000407 
31. Hacimusalar Y, Kahve AC, Yasar AB, et al. Anxiety and hopelessness levels in COVID-19 pandemic: a comparative study of healthcare professionals and other community sample in Turkey. J Psychiatr Res. 2020;129:181-188. doi:10.1016/j.jpsychires.2020.07.024

32. Alharbi A, Alharbi S, Alqaidi S. Guidelines for dental care provision during the COVID-19 pandemic. Saudi Dent J. 2020;32(4):181-186. doi:10.1016/j.sdentj.2020.04.001

33. Elangovan S, Mahrous A, Marchini L. Disruptions during a pandemic: gaps identified and lessons learned. J Dent Educ. 2020;84 (11):1270-1274. doi:10.1002/jdd.12236

34. Kochhar AS, Bhasin R, Kochhar GK, et al. Provision of continuous dental care for oral oncology patients during \& after COVID-19 pandemic. Oral Oncol. 2020;106:104785. doi:10.1016/j. oraloncology.2020.104785

35. Sharaf RF, Kabel N. Awareness and knowledge of undergraduate dental students about the signs and symptoms of Corona viral infection (COVID-19), and the required infection control measures to prevent its spread. Bull Natl Res Centre. 2021;45(1):32. doi:10.1186/s42269-021-00494-1

36. Peng X, Xu X, Li Y, et al. Transmission routes of 2019-nCoV and controls in dental practice. Int J Oral Sci. 2020;12(1):9. doi:10.1038/ s41368-020-0075-9

37. Virdi MS, Sood M. Effectiveness of a five-step method for teaching clinical skills to students in a dental college in India. J Dent Educ. 2011;75(11):1502-1506. doi:10.1002/j.0022-0337.2011.75.11.tb05209.x

38. Abdulghani HM, Sattar K, Ahmad T, et al. Association of COVID-19 pandemic with undergraduate medical students' perceived stress and coping. Psychol Res Behav Manag. 2020;13:871-881. doi:10.2147/ PRBM.S276938

39. Sukumar S, Dracopoulos SA, Martin FE. Dental education in the time of SARS-CoV-2. Eur J Dent Educ. 2020;25:325-331. doi:10.1111/eje. 12608
40. Garg A, Marji A, Goyal S, et al. A case of COVID-19 with memory impairment and delayed presentation as stroke. Cureus. 2020;12(8): e10025.

41. Heneka MT, Golenbock D, Latz E, et al. Immediate and long-term consequences of COVID-19 infections for the development of neurological disease. Alzheimers Res Ther. 2020;12(1):69. doi:10.1186/ s13195-020-00640-3

42. Zhou H, Lu S, Chen J, et al. The landscape of cognitive function in recovered COVID-19 patients. J Psychiatr Res. 2020;129:98-102. doi:10.1016/j.jpsychires.2020.06.022

43. Ardila A, Lahiri D. Executive dysfunction in COVID-19 patients. Diabetes Metab Syndr. 2020;14(5):1377-1378. doi:10.1016/j. dsx.2020.07.032

44. Jahan S, Araf K, Griffiths MD, et al. Depression and suicidal behaviors among Bangladeshi mothers of children with Autism Spectrum Disorder: a comparative study. Asian J Psychiatr. 2020;51:101994. doi:10.1016/j.ajp.2020.101994

45. Mamun MA, Griffiths MD. A rare case of Bangladeshi student suicide by gunshot due to unusual multiple causalities. Asian $J$ Psychiatr. 2020;49:101951. doi:10.1016/j.ajp.2020.101951

46. Gaş S, Ekşi Özsoy H, Cesur Aydın K. The association between sleep quality, depression, anxiety and stress levels, and temporomandibular joint disorders among Turkish dental students during the COVID-19 pandemic. Cranio. 2021;1-6. doi:10.1080/08869634.2021.1883364

47. Stormon N, Sexton C, Ford PJ, et al. Understanding the well-being of dentistry students. Eur J Dent Educ. 2021. doi:10.1111/eje.12666

48. Hakami Z, Khanagar SB, Vishwanathaiah S, et al. Psychological impact of the coronavirus disease 2019 (COVID-19) pandemic on dental students: a nationwide study. J Dent Educ. 2020;85:494-503. doi:10.1002/jdd. 12470
Psychology Research and Behavior Management

\section{Publish your work in this journal}

Psychology Research and Behavior Management is an international, peer-reviewed, open access journal focusing on the science of psychology and its application in behavior management to develop improved outcomes in the clinical, educational, sports and business arenas. Specific topics covered in the journal include: Neuroscience, memory and decision making; Behavior modification and management; Clinica applications; Business and sports performance management; Social and developmental studies; Animal studies. The manuscript management system is completely online and includes a very quick and fair peer-review system, which is all easy to use. Visit http://www dovepress.com/testimonials.php to read real quotes from published authors. 